\title{
A VALUATION OF PUBLIC SPACES: SELECTED RESEARCH RESULTS
}

\author{
Sławomir Palicki, PhD \\ Department of Spatial and Environmental Economics \\ Poznań University of Economics \\ e-mail:s.palicki@ue.poznan.pl
}

\begin{abstract}
The aim of the study is to draw attention to the fact that the value of public spaces has an interdisciplinary character, and should be viewed as such. The multifaceted function of public spaces requires a thorough recognition of their role and functioning in a city, especially from the estate management point of view. The fact that well-designed and managed public spaces have a great effect on social, cultural, market and communicative behavior, makes them an axis of urban development. The extent to which public spaces affect neighboring property markets, especially when it comes to the commercial segment, is also very important. The way in which a public space is utilized, is an incentive to search for optimal directions as to how a given property should function.

The research results presented in the present paper concern three case studies of big Polish cities Poznań, Gdańsk and Wrocław. The research incorporated sociological survey tools (questionnaire), indepth interviews and observations.
\end{abstract}

Keywords: public spaces, value, real estates, entrepreneurs, social groups.

JEL Classification: R30.

Citation: Palicki S., (2013), "A Valuation of Public Spaces. Selected Research Results", Real Estate Management and Valuation, vol. 21, no. 1, pp. 19-24.

DOI: 10.2478/remav-2013-0003.

\section{Introduction}

Public spaces are essential for the proper development of urban and central city functions, however, their particular types are known to affect the users' perception, behavior, and utilization to a different extent. Utilizing the knowledge concerning the value of public spaces in order to control and recognize behaviors of the local market, along with the conscious and proper management of their particular types are key issues. The creation of public spaces does not remain unseen when it comes to the reactions of subjects investing in real properties - properly interpreting the function of a given space provides an argument for the optimization of its use.

The paper aims to present some selected results of the public space analyses of big Polish cities, conducted within a ministerial grant (project no. 83151, project manager: M. MATUSIAK, executors: M. NOWAK, S. PALICKI, K. STACHOWIAK).

Due to the limited size of the article, only chosen analyses and conclusions were presented, especially those concerning public space valuation and evaluation, and the manners of public space utilization by different social groups. The research was conducted in three big Polish cities - Poznan, Gdansk, and Wroclaw. Where entrepreneurs are concerned - the research results show only those details connected with the subjects from Poznan (only those results were available so far). Concerning the second part of case studies dedicated to social groups, the analyses include all three of the mentioned cities. The results of research presented in the second and third part of the article are case 
studies. They were conducted in a parallel manner, exploring the problem of public space valuation and at the same time, questioning its relatively different dimensions.

A full presentation of the research shall be available within a year, as an English monograph. Due to the fact that, as far as merit is concerned, the article is directly related to last year's theoretical publication (PALICKI, 2012), another methodological and literature analysis concerning the concept and research was deliberately disregarded in this article.

\section{Public space from the entrepreneurs' point of view}

The research made use of a survey questionnaire. Most of the survey questions were closed, with a 5grade Lickert scale. The reactions and feelings of 28 entrepreneurs occupying commercial real estate within the city centre of Poznan, concerning the quality of public spaces and their entrepreneurships themselves were researched into. In the case of some issues, the dynamics of the phenomenon in five year retrospect were also checked. The issues analyzed were: the general evaluation of the place, the willingness to change the place, the feeling of security, the quality of the transport network, the evaluation of cost changes and the profitability of a business (five year retrospection), and finally the evaluation of real estate value changes (similarly, over the last 5 years). It must be mentioned that the last issue was not a case of evaluation by experts, but by entrepreneurs. Their feelings concerning the issue were researched.

The general image of the situation, seen as the place of the entrepreneurship, is mainly positive. Around $62 \%$ of the respondents described the place in a positive or very positive manner. It can be supposed that the main circumstances behind the evaluation were the perception of the surroundings and the localization.

What is more, the question concerning the potential decision of moving the company from its current location proved to be of low acceptance, declared by merely $28.5 \%$ of the respondents. Companies located within the Old Town showed a higher level of acceptance (37.5\%). Among the reasons behind the potential change of the business location, entrepreneurs pointed out the lack of perspectives for running a profitable business at the current location.

The feeling of security, among both citizens of a given public space and entrepreneurs, is also important. Perceived financial stability is mainly conditioned by a positive evaluation of the security. About $46 \%$ of the respondents believe that their surroundings meet the safety requirements. However, $41 \%$ seemed to have a contrary point of view. Only $4 \%$ of the respondents remained undecided. What was established as to the feeling of security, is that the society is highly polarized.

The transport network was evaluated positively - over $89 \%$ of subjects evaluated this element as good, or very good. There were no negative opinions. However, the evaluation of the quality of the transport network located in a city center could not have been other than good or very good provided that the issue was viewed rationally by the respondents.

To what extent do the surroundings (or rather people functioning within the surroundings) pay attention to a business? The reaction to this question was positive. The area analyzed in the research has become one of the most recognizable and well-defined spaces in the central part of Poznan (the Old Market Square, the Jeżycki Market). This fact may have influenced respondents opinions and contributed to the very high number of positive associations - 70\%. Negative associations, on the other hand, constituted only $7 \%$ of the total responses.

Changes concerning the costs of running a company in the last 5 years concern mainly the period of the macroeconomic crisis. The negative evaluation ( $96 \%$ of all responses) was surely influenced by the general negative feelings regarding the economy.

To complete the picture of the economic situation during a crisis, the survey included a question concerning the changes in profitability over last 5 years. Yet again, the results are a bit worrying; however, the negative feelings concerning the extent of the crisis turned out to be a bit lower than those concerning the costs of running a company - 70\% of all the answers.

The last part of this fragment of the research was the question concerning the changes of the (market) value of properties. Here, many of the respondents failed to respond to the issue (over 10\% were unable to answer). This might be the consequence of the lack of knowledge on the topic.

It should be explained that answers such as "rather not" or "definitely not" in a wider commentary from the pollsters point of view, were presented to respondents as "the value has rather decreased", or "the value has definitely decreased". It is difficult to draw a definite conclusion concerning the feelings of entrepreneurs. It seems that, according to their subjective evaluation, there has been a shift towards 
a slight decrease in property value. There were few extreme answers (a large increase of value - $16 \%$, a large decrease - $8 \%$ ) in the presence of $44 \%$ neutral answers (suggesting a stable value of properties throughout the last 5 years), which may suggest that the respondents were rather conservative in voicing their opinion. Again, however, this might be explained by their lack of certainty concerning the actual course of the phenomenon. As a result, the cognitive value of the obtained answers must unfortunately be seen as unsatisfactory and doubtful.

The entire research has observed a low level of the entrepreneurs' awareness concerning the actual importance and influence of the surroundings and location on their businesses. Such a fact is worrying, especially due to the fact that it is rather a matter of the lack of understanding than of rejecting the actual significance of a given area, including the public spaces. It can be assumed that the low perception of relations between the quality of a space, location and the efficiency of entrepreneurships is an internal malfunction, interpretative aberration, or a gap in awarness.

Entrepreneurs present an internally incoherent and incomprehensible dualism of how they perceive the reality surrounding them. The quality and adaptation of the space, location and transport facilities, along with a low readiness to move from the given place are accompanied by the lack of logical transfer to results concerning the property value, the success of running a business, etc. The deep economic crisis may, to some extent, explain this aberration.

A full image of the situation may lead to the conclusion that the ability to evaluate public space by observing the key features and the price-making attributes of properties, lies out of the full and conscious perception of subjects running a business in commercial areas. It seems that the level of decision-making maturity regarding location or, in general, the depth and cohesion of the property market, is far from optimal.

\section{Utilizing and valuating public spaces in the social groups' perspective}

The intention of the research was to create partial models, capturing the space valuation done by particular social groups, and a general model. It created the necessity of empirically capturing the specifications of utilizing particular (analytically chosen) types of spaces (representative squares and markets, market places, open spaces), using the simplest possible tools. The selection of the types of public spaces was deliberate and focused on illustrating three bands of attractiveness and the different scales of the spatial influence of the surroundings: representative squares and markets in the wholecity scale, market places in the scale of the district, and open spaces between blocks of flats in the local scale. The research made use of sociological survey tools (questionnaires), in-depth interviews, and observations. Both the evaluation of certain spaces in regards to features (using them over time), and declarations concerning the way of utilizing a given space proved to be interesting. Questions concerning spaces were partially devoted to testing the valuation criteria, which were created on the basis of literature, against the model.

The basic research tool was a questionnaire conducted among 858 citizens (market researchers visited every third flat in the blocks of flats chosen for the surveys), whose places of residence were located in the proximity of public spaces undergoing analysis, in the selected cities. In addition to questions concerning the frequency of using a space, the questionnaire, in the typical survey tool form, contained an expanded set of sentence on which the respondents were asked to take a stance. The sentences were directly related with the various aspects of valuating a space - social, economic, urban, ecological, cultural, and symbolic. Observations and in-depth interviews were used as additional survey tools.

A general hypothesis concerning the temporary usage of a public space was drawn. The hypothesis searched for relations between the frequency of usage, specific manner of usage and user characteristics, which is an approach to understanding the empirical mechanisms concerning the valuation of particular public spaces.

When it comes to market places, the respondents most frequently reported utilizing the space often (several times a day, a couple of times per week), which constituted $65 \%$ of all the answers. Different behaviors were declared, when it comes to representative squares and markets. The differences lie in the intensity of usage, which is lower than in the case of market places. A regularity of using representative markets and squares applies to half of respondents (46.8\%). People tend to do the shopping a bit more often than simply spend time at these locations, which suggests a dominant role of particular motivations or needs. 
Open spaces are used more often. The declaration of their everyday usage was about $45 \%$, which might come off as surprising. The relatively high number, along with significant differentiation among the remaining answers (several times a week, seldom etc.), might have been caused by the choice of the researched space. These were open spaces within housing estates, in the direct neighborhood of the respondents' place of residence. Supposedly, in such cases, the recreational functions should also be completed by the transport function. The open spaces surrounding housing estates are used very often and may be utilized in various ways (which differ from those of commercial spaces). The dominant function of these spaces seems debatable in that there is no evidence to confirm that it is the recreational function.

Within the part of the survey which contained questions concerning the particular hours of during which a space is utilized, the differences between the various spaces have become even more noticeable. Representative markets and squares were used systematically (several times a day, a couple of times per week), between 9 am and $9 \mathrm{pm}$, with the higher intensity observed in the afternoon - evening period ( $1 \mathrm{pm}-9 \mathrm{pm})$.

The time period of utilizing retail spaces is shorter that in the case of the representative squares and markets (from 9 am to $5 \mathrm{pm}$ ), and is highest between 9 am and $1 \mathrm{pm}$, during the opening hours of various retailers operating in such types of spaces. The open spaces of housing estates were used often and intensively throughout the entire day, from 9 am to $9 \mathrm{pm}$.

The analysis of space utilization where socio-professional groups are concerned (DOMAŃSKI 2004; DOMAŃSKI AND OTHERS 2007] has provided some very interesting conclusions. A total of four groups which differed substantially according to socio-economic criteria were isolated from the entire research group. These were: a) the high social level - top management, technical and non-technical intelligentsia; b) the labor force - people who hold middle or low positions in their jobs c) students, people who are not yet working, but will soon enter the job market, and d) pensioners.

The users' quantity analysis shows that the usage of spaces is relatively equal among the particular types of the labor force. However, the results differ when it comes to pensioners and students, that is groups of people who do not work. The former utilize representative squares and markets in the morning and afternoon, whereas the latter visit them later during the day. The results do not differ substantially when it comes to market places - the main times of use are between late morning hours and the early afternoon. This may suggest the existence of a universal "pattern" of using both types of spaces, which is, however, only characteristic of people who are no longer or not yet employed.

Data concerning the open spaces of housing estates does not differ considerably from that concerning other types of spaces. When it comes to the labor force, usage during the afternoon is mainly declared, whereas those who do not work use these spaces mainly in the morning. Similarly to representative squares and markets, the time of use is distributed between 9 am and $9 \mathrm{pm}$, though it is important to note that usage between $1 \mathrm{pm}$ and $5 \mathrm{pm}$ (the time of returning from work) is declared more often $(36.36 \%)$.

There is a statistical relationship between the frequency of usage and the times of using particular types of the public spaces (based on the survey) in the case of representative squares and markets, and to a lesser extent, open spaces. Such spaces are more systematically and more often used in the afternoons and evenings. Similar conclusions may be drawn on the basis of in-depth interviews.

There is a difference between representative squares and markets, and inner-city market spaces. The difference mainly concerns a smaller intensity of using the latter in the afternoon, which is the result of the specific character of inner-city trade, which is focused on local demand and targets mainly the less mobile inhabitants of the city.

Detailed characteristics concerning the types of space were obtained using specific answer frequency analysis. Relationships between the answers to various questions concerning the nature of utilizing a space were determined using correlative analyses, exploratory factor analysis, and the ranking formula. Only those relations, the existence of which can be statically proven were subjected to analysis. Using the aforementioned statistical procedure is based on the conviction that the study matter concerns variable quantities. This is not entirely true when it comes to the Licker scale, however, using such a tool allows for such procedures (COSTELLO AND OSBORNE 2005].

Among the research hypotheses formulated for this particular part of the research, the following proved to be the most important: those assuming the existence of distinctive ways of utilizing particular public spaces, those suggesting a different manner of their valuation and acknowledging 
the fact that there are separate hierarchies of importance for the particular types of spaces, and those concerning the highlighted aspects of their functioning.

The general and most important conclusion drawn from the empirical analysis is that the social aspects of the respondents' evaluations clearly characterize all types of spaces. Such social aspects are not assigned to one particular type of space, but dominate public spaces in general, regardless of their type. This conclusion is not surprising, as it has already been presented in city-sociology literature (WALLIS 1979; ZNANIECKI AND ZIÓEKOWSKI 1984]. Some of the less obvious observations concerned the detailed analyses of particular types, which in certain cases were paradoxically similar concerning non-social aspects, or significantly different.

The results obtained through factor analysis and when searching for statistical relationships between opinions are not satisfactory where the hypothesis of separating public space types is concerned. Nevertheless, there are some important characteristics which differentiate the particular types of spaces. Importantly, on the basis of the obtained results, representative squares and markets and market places shall be treated as elements of a compact structure rather than separate types of spaces. It seems that the most important reason behind this is the inner-city location of such spaces. The case looks differently when it comes to housing estates and open spaces. Even though a certain part of the correlative analysis points to similarities, it is possible to identify important reasons which support their dissimilarity in terms of both aesthetical and functional aspects of a given space.

The exploratory factor analysis allows the typical scopes of aspects and valuation to be narrowed down to three synthetic factors a) socio-identification, concerning both social and symbolic aspects, b) applied, concerning mainly the economic aspect, and c) functional, concerning the spatial adjustment issues and transport.

It is worth noting that there are some universal features of public spaces and distinctive features of their particular types. The most important aspect proves to be the social one, which lies within the registered factors of each and every type of space. Surprisingly, the "applied" factor, which in the applied scheme concerns mainly the financial aspects, has a smaller significance. It concerns mainly representative squares and markets and market places, not open spaces in housing estates.

Physiognomic and cultural aspects appeared in the relationship with social aspects, mainly concerning representative squares and markets, but also, which may come as a surprise, market places. When it comes to the social features of respondents and how they view a given space, it is necessary to highlight the relationship between the utilization of public spaces and the age and education of the respondents.

Summing up, it is worth noting that questionnaire surveys conducted among the inhabitants of particular areas did not fully explore the issue. City centers are used not only by local inhabitants. A fundamental difference between inner-city spaces, and housing estates was observed here. People who are not inhabitants of a given space may differ considerably from the local citizens. The views of "guests" concerning these spaces were established based on in-depth interviews, which does not allow for a direct and complete comparison, but is important where quantity verification and the general study subject are concerned.

\section{Conclusions}

1. Entrepreneurs see the features of public spaces, define them, and seemingly appreciate the location, and attributes of the surroundings. Unfortunately, the level of consciousness does not exceed the level of passive perception and, therefore, does not result in the ability to actively evaluate the direction and importance of desirable and attractive public spaces or their features in the proximity of commercial areas, where various kinds of businesses are run.

2. Among the types of public spaces isolated for purposes of the research (representative squares and markets, market places, housing estate open spaces), some differences were observed when it comes to their usage over the course of a day. However, these differences were not fundamental. The utilization of representative squares and markets was especially similar to that of inner-city market places. However, the aspects assigned to housing estates were found to differ. The intensity of utilizing retail spaces (market places) was the highest among all of the researched space types. It is probable that research results in their final form will make it possible to verify the correctness of the thesis formulated in this article. 
3. Social and symbolic aspects seem to be of utmost importance as far as the functioning of spaces under evaluation is concerned. At the same time, they are not distinctive of particular types of spaces, but are rather permanent for all the space types, in public space on the whole. Distinctive aspects, which appear as a second row of aspects, concern mainly those which are economic (space usage in factor analysis) and functional. The specific character of the presence of other aspects is such a complex issue that it may actually constitutes a basis for generating new, separate types of public spaces.

\section{Bibliography}

Costello A.B., OsBorne J.W., 2005, Best Practices in Exploratory Factor Analysis: Four Recommendations for Getting the Most From Your Analysis, "Practical Assement, Research \& EvaluationVolume" 10, Number 7, July 2005, Internet: http://pareonline.net/pdf/v10n7.pdf

DOMAŃSKI H., 2004, Struktura społeczna, WYDAWNictwo NAUKOwE SCHOLAR, Warszawa.

DOMAŃSKI H. I INNI., 2007, Nowa klasyfikacja i skale zawodów. Socjologiczne wskaźniki pozycji społecznej w Polsce, Wydawnictwo IFIS PAN, Warszawa.

PALICKI S., 2012, Wartościowanie przestrzeni publicznych, (w:] ŹRÓBEK S., 2012, Studia i Materiaty Towarzystwa Naukowego Nieruchomości, vol. 20 no. 3, s. 111-122, Olsztyn.

WALLIS A., 1979, Informacja i gwar, PIW, Warszawa.

ZNANIECKI F., ZIÓ£KOWSKI J., 1984, Czym jest dla ciebie miasto Poznań: dwa konkursy 1928 - 1964, PWN, Warszawa. 